\title{
Information Systems Quality Level and Its Impact on the Strategic Flexibility: A Field Study on Tourism and Travel Companies in the Jordanian Capital Amman.
}

\author{
Abood Saleh Ahmad AL-Adwan \\ Al-Balqa Applied University, Jordan \\ E-mail: aboodaadw@hotmail.com
}

Received: June 23, 2017 Accepted: July 12, 2017 Online published: August 4, 2017

doi:10.5296/ijhrs.v7i3.11344 URL: https://doi.org/10.5296/ijhrs.v7i3.11344

\begin{abstract}
This study aimed to analyze the impact on the Information Systems Quality on the Strategic Flexibility in Jordanian tourism and travel companies in capital Amman. To achieve the goals of this study, the questionnaire has been developed to collect data which has been distributed over (130) individual through the survey population, (100) individuals had been studied, which represents $77 \%$. The study reached to a group of results: 1 . the perceptions of the people in question were fluctuating between high and moderate toward the level of the availability of Information Systems Quality and all of its dimensions in the Jordanian tourism and travel companies in capital Amman. Whereas their perceptions of the Strategic Flexibility were all moderate. 2. There is a statistical significance impact on the Information Systems Quality dimensions (Usability, Availability, Response Time) on the Strategic Flexibility for Jordanian tourism and travel companies in capital Amman. The study recommends the questioned companies' administrations to draw attention to the perspectives of the Information Systems users when updating the systems design to improve the dimension of the Systems adaptation, also to bring the researchers attention to do more researches concern the Information Systems Services Quality, Information Quality and the Strategic Flexibility to complete the elements of Information Systems efficiency.
\end{abstract}

Keywords: Information System Quality, Strategic Flexibility, Tourism \& Travel Companies.

\section{Introduction}

The competition- increasing among business organizations is the most important thing that distinguishes the modem environment, so the business organizations strive towards to build the latest methods to achieve their goals: viability, growth, and continuity. This is not limited to employ the Information Systems on their business and activities only, but to the pursuit of improving the Information Systems Quality level through the scrutiny of features and 
Information Systems processes that insure efficiency and benefits wanted from the system. Furthermore, the Strategic Flexibility became one of the most important administrative development fields that represent the ability of expect the changes in the external environment and the responsiveness for it.

The tourism and travel companies are considered one of the most important economic activities which support the Jordanian economy. These companies are keen to adapt the best Information Systems features that insure the quality of its processes and activities. Moreover, these companies are of the organizations that need the Flexibility in its strategies due to the complication and speed of the environment they are working in. They need the rapid response for opportunities and threats in their environment in order to achieve competition and success. This study sheds the lights on the concept: Information Systems Quality and the Strategic Flexibility through analyzing Information Systems Quality and its impact on the Strategic Flexibility of Jordanian tourism and travel companies in the capital Amman.

\subsection{Problem of Study}

The Strategic Flexibility is considered one of the most important requirements to achieve success for the modern organizations while dealing with the rapid and complicated environmental changes, its means is expecting the future changes and amending its methods of dealing with it by seizing opportunities and facing challenges. The general indicators seem obvious regard the information systems applying by the companies. Furthermore, the Information Systems adaptation in tourism and travel companies is considered unquestionable, although we can't determine the level of the Information Systems Quality in it. Besides, the Strategic Flexibility applying level for these companies is unknown too. Also, the researcher as a follower for general indicators is feeling ambiguity whether there is impact on the Information Systems Quality on improving the level of the Strategic Flexibility and in front of these indicators and what is going around it, like the lack of knowledge of the researcher in respect of Information Systems Quality level and whether it has impact on the Strategic Flexibility or not. This study attempts to clarifying ambiguity about the understanding of the employees serving in tourism and travel companies for the level of Information Systems Quality and its impact on improving the Strategic Flexibility. The problem of the study can be summarized by answering the following main question: what is the level of the Information Systems Quality and its impact on the Strategic Flexibility from the perspective of the employees serving in tourism and travel companies in Jordan capital Amman?

\subsection{Questions of Study}

The study is trying to answer the following questions:

1. What are the perceptions of the people in question regards to the Information Systems Quality levels in tourism and travel companies from the perspective of the employees serving in Jordan capital Amman?

2. What are the perceptions of the people in question regards to the Strategic Flexibility levels in tourism and travel companies from the perspective of the employees serving in Jordan 
capital Amman?

\subsection{Importance of Study}

The importance of this study starts from its use of concepts that characterized by modernism and it has considerable concern from the researchers in Information Systems field, and the practitioners in public and private organizations. These two concepts are the Information Systems Quality and Strategic Flexibility, especially with the limitation of researches and studies that cared about those two topics in Arab region in general, and in the Hashemite Kingdom of Jordan in particular.

Moreover, this study is considered from the academic side a baseline for more subsequent studies in knowledge industry related to the Information Systems Quality and Strategic Flexibility, in reason it depends on scientific methodology based on a combination of desk study method aimed to clarify the theoretical dimensions related to the subject- this is through extrapolate the main findings of the literature of management in study field, in addition to the usage of field survey method to stand on the impact on Information Systems Quality on the Strategic Flexibility from the perspective of the employees in tourism and travel companies serving for Jordan capital Amman which helps in providing applied knowledge about the importance of Information Systems Quality and Strategic Flexibility.

\subsection{Goals of Study}

In general, this study aimed to analyze the impact on Information Systems Quality on from the perspective of the employees in tourism and travel companies serving in Jordan capital Amman besides achieving the following sub-goals:

1) Learn about the perceptions of the people in question regards to the Information Systems Quality level in tourism and travel companies from the perspective of the employees serving in Jordan capital Amman.

2) Learn about the perceptions of the people in question regards to the Strategic Flexibility level in tourism and travel companies from the perspective of the employees serving in Jordan capital Amman.

3) Attempt to provide suggestions and recommendations to the administrators of tourism and travel companies working in Jordan capital Amman based on the study results.

\subsection{Hypotheses of Study}

First main hypothesis: H01 There is no statistical significance impact at the significance level $(\alpha \leq 0.05)$ for the Information Systems Quality and its dimensions: (Adaptability, Availability, Reliability, Response Time and Usability) on the Strategic Flexibility in tourism and travel companies working in Jordan capital Amman. There are sub- hypotheses that stemmed from the first main hypothesis:

First sub-hypothesis: H01-1 There is no statistical significance impact at the significance level $(\alpha \leq 0.05)$ for the Information Systems Quality and its dimensions: (Adaptability, Availability, Reliability, Response Time and Usability) in Market Flexibility dimension as 


\section{Macrothink}

International Journal of Human Resource Studies

ISSN 2162-3058

2017, Vol. 7, No. 3

one of the Strategic Flexibility dimensions in tourism and travel companies working in Jordan capital Amman.

Second sub-hypothesis: H01-2 There is no statistical significance impact at the significance level $(\alpha \leq 0.05)$ for the Information Systems Quality and its dimensions: (Adaptability, Availability, Reliability, Response Time and Usability) in Product Flexibility dimension as one of the Strategic Flexibility dimensions in tourism and travel companies working in Jordan capital Amman.

Third sub-hypothesis: H01-3 There is no statistical significance impact at the significance level $(\alpha \leq 0.05)$ for the Information Systems Quality and its dimensions: (Adaptability, Availability, Reliability, Response Time and Usability) in Capabilities Flexibility dimension as one of the Strategic Flexibility dimensions in tourism and travel companies working in Jordan capital Amman.

\section{Theoretical Framework}

This figure demonstrates the dimensions of the Independent Variable (Information Systems Quality) which are: (Adaptability, Availability, Reliability, Response Time and Usability) and the dependent variable dimensions (Market Flexibility, Product Flexibility, and Capabilities Flexibility).

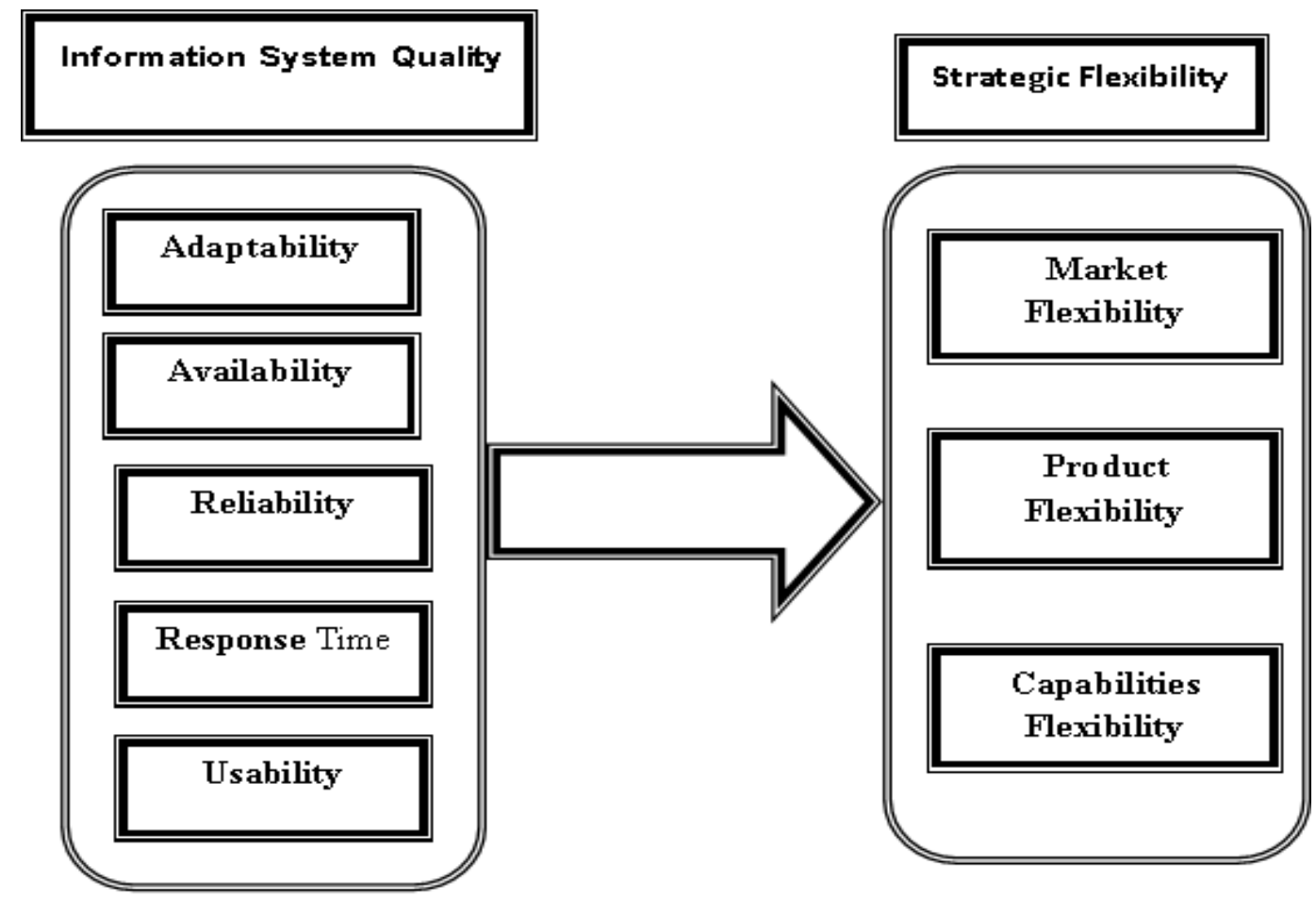

Figure 1. Theoretical Framework. 


\section{Al Macrothink}

\section{Study Methodology}

The study will adapt the analytical descriptive approach that contained a desk survey by referring to ready references and sources to build the theoretical framework of study, and the field survey to collect data by the study's tool (questionnaire).

\subsection{Study Sample and Population}

The survey population consists of all who works in tourism and travel companies of Jordan capital Amman, which they are (130) individual random sample of (100) individuals has been selected which represent $(77 \%)$ of the survey population.

\subsection{Tool of Study}

The (questionnaire) is the study tool which has been developed based on previous studies and the theoretical framework and it consisted of three parts:

The first part: consists of study's sample features according to personal and employment variables (Qualifications, Employment Experience, and Employment Level).

The second part: contained (25) paragraphs that have been distributed to include the independent variable dimensions (Information Systems Quality). Its paragraphs have been formulated with the study (Al-Hudhaif, 2010, Bach, Christian, 2011 Gryna \& Others, 2007) used as a guide.

The third part: contained (17) paragraphs that have been distributed to include the Dependent Variable dimensions (Strategic Flexibility) Its paragraphs have been formulated with the study (Abbott \& Banerj 2003, Lamalfa, 2008) used as a guide.

\subsection{Study's Tool Ratified}

To make sure of the study ratified, it has been reviewed for (8) of teaching staff in different universities in Jordan and on specialized and experts in the study subject in order to make sure that the questionnaire paragraphs are appropriate to the measurement wanted and if the paragraphs are belonging to the dimensions that they are allocated to measure it. After taken back the questionnaire, some amendments have been done on the questionnaire paragraphs and formulated it in the final forms that serve the study purposes.

\subsection{Stability of Study's Tool}

The stability coefficient has been extracted according to Cronbach's Alpha equation to make sure of the internal coherence in it's final form, and to every variable with its all dimensions. The stability values were high and indicate stability and coherence between the tool paragraphs. The following table manifests the values of stability coefficients for the dependent and independent variables of the study: 


\section{Macrothink}

International Journal of Human Resource Studies

ISSN 2162-3058

2017, Vol. 7, No. 3

Table 1. Coefficients of scale and areas stability and Coefficients of stability:

\begin{tabular}{|l|l|l|l|}
\hline $\begin{array}{l}\text { Information Systems } \\
\text { Quality Dimensions } \\
\text { Independent Variable }\end{array}$ & $\begin{array}{l}\text { Internal } \\
\text { Coherence }\end{array}$ & $\begin{array}{l}\text { Strategic Flexibility } \\
\text { dimensions } \\
\text { Dependent Variable }\end{array}$ & $\begin{array}{l}\text { Internal } \\
\text { Coherence }\end{array}$ \\
\hline Adaptability & 0.90 & Market Flexibility & 0.89 \\
\hline Availability & 0.80 & Product Flexibility & 0.90 \\
\hline Reliability & 0.86 & Capabilities Flexibility & 0.88 \\
\hline Response Time & 0.80 & & \\
\hline Usability & 0.90 & & \\
\hline
\end{tabular}

\subsection{Statistical Treatment}

To answer the study questions and examine the validity of its hypotheses, the researcher used the Analytical and Descriptive Statistics methods as (SPSS. V17) and the following statistical methods:

1. Iterations and percentage to describe the study's sample features, and counting the Medians and Standard Deviations to answer the study questions.

2. Multiple Regression Analysis to examine the validity of study forms and the impact of the Independent Variable and its dimensions on the Dependent Variable and its dimensions.

3. Stepwise Multiple Regression Analysis to examine the entrance of the Independent Variables in the prediction equation of the Dependent Variable.

4. (ANOVA) analysis to examine the impact of the personal and employment on the perceptions of the people in question about the Independent and Dependent Variables and its dimensions, in addition to (LSD) test for dimensional comparisons in case there are differences.

\subsection{Procedural Definitions}

A. The Independent Variable: the information system quality represents the quality of the processing quality in system which are system's availability and it ability to adapt, also its ability to response and to be reliable, ability to response and usability. It consists of the following dimensions:

1) Availability: the ability of the Information System supplies and facilities to remain in a status that it can achieve functions in the right way under specific circumstances and with the assumption of the Availability of all wanted recourses.

2) Reliability: it represents the System success in achieving goals that it has been set for it accurately and in reliable way during specific period of time.

3) Adaptability: the system ability to adapt according user's demands and circumstances.

4) Response time: the System ability to response for user request.

5) Usability: indicates for what level the Information System is practical and appropriate to 
use.

B. The Dependent Variable: Strategic Flexibility: the ability of the travel and tourism companies working in Jordan capital Amman to response rapidly for the opportunities and environmental threatens. I current study, the Strategic Flexibility will be measured based on the following Variables (Appott \& Banerj ,2003, Lamalfa, 2008):

1) Market Flexibility: it indicates the ability of the travel and tourism companies working in Jordan capital Amman to reevaluate its marketing effort in local and international market within short period of time that in reason of the response for environmental changes.

2) Product Flexibility: indicates to the travel and tourism companies working in Jordan capital Amman ability to serve it services to be appropriate in most of these international and local market in addition to serve it in short time and competitive prices.

3) Capabilities Flexibility: indicates the travel and tourism companies working in Jordan capital Amman ability to take full advantage of the new resources and the most effectiveness to fulfill its customers' needs.

\subsection{Theoretical Framework of Study: Information System Quality}

The Concept of Management Information System:

A lot of literatures concern to explain and manifest the concept of Management Information System which became one of the basics for any organization. Somebody defined it as managerial or technical concept, and another combined the two concepts. Davis, 1985 explained that the Management Information System is a complementary system between human and machine to provide the information required that supporting the managerial processes and decision- making positions in any organization. This system is stand for using the hardware, software, manual procedures, managerial decision models, and data bases. Whereas O'brien,2011 saw that the it is a "combination of individuals, devices, tools, programs, connection networks, data sources and bases, and the orders that store, retrieve, transform and disseminate information that it is needed by the organization in the right time and the right purposes". Vasheney, Mandan,2011 clarified that the Management Information Systems are a group of sub-systems which based on data bases in any organization and the function of such systems is to store, organize, transform the information and other functions.

The researcher sees through all previous explanations that we can define the Management Information Systems as group of complementary components which consist of devices, basic and sub tools, supported software, connection channels and networks, in addition to the qualified human resources that are working with each other smoothly and in full harmony in order to get the data and information which help the administrations to do their missions: planning, execution, and control all organization's departments. (Laudon \& Laudon, 2007)

\subsection{Types of Management Information Systems}

There are four main types of the management information systems which serve three vital managerial levels in the organization (Laudon \& Laudon, 2007, p43-54) which are illustrated 
in figure no. (2):

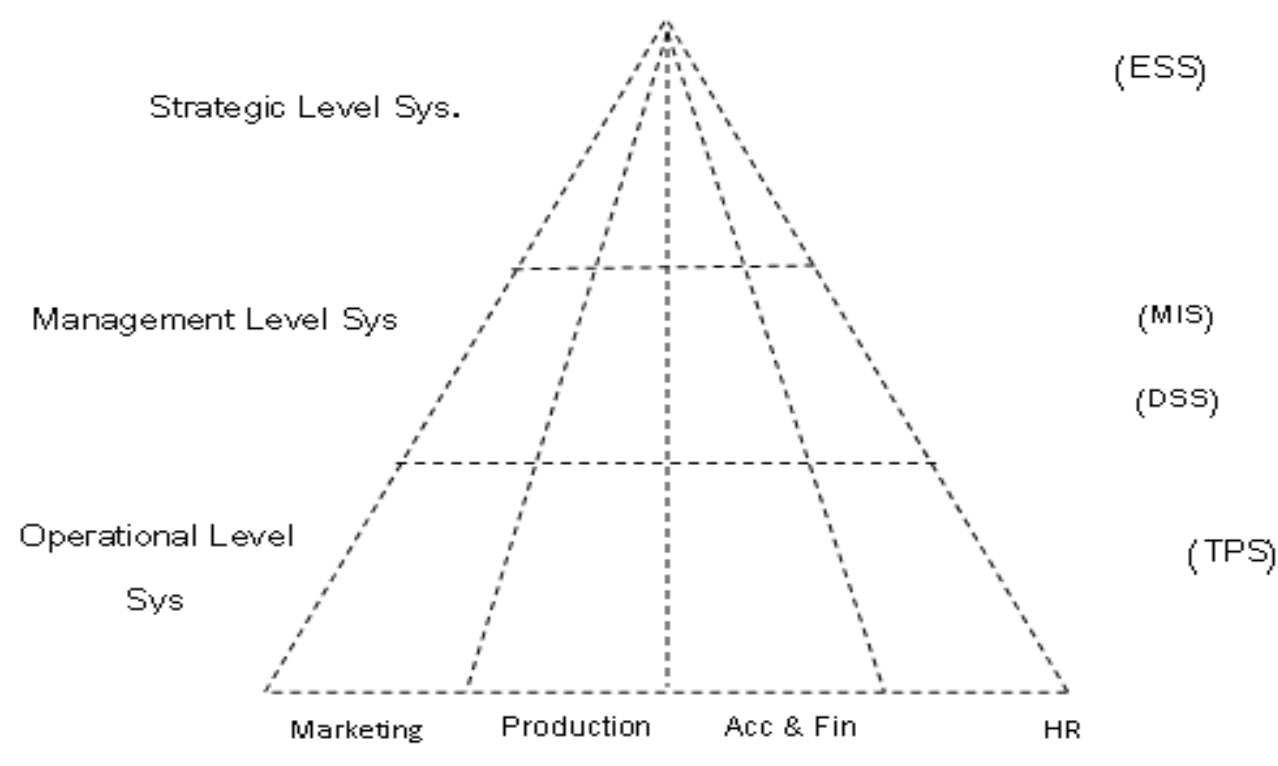

Figure 2. Types of Management Information Systems

The first one is Transaction Processing Systems (TPS) which based on computerized systems that working on execute and register day to day works that are needed to execute the organization's activities. The Transaction Systems are classified at this level into five systems: sales and marketing systems, manufacturing and production systems, accounting and financial systems, and the human resources systems. Whereas Decision Support Systems (DSS) are used in management levels to help them in taking unique, fast-changing decisions and the decisions that cannot be determined previously. The information coming from transaction levels are being the main source for the data that used in the management levels. Furthermore, the Management Information Systems (MIS) are considered a group of systems that have been designed especially to help and serve the management level activities in business organizations, and its main function is providing information in reports about the organization's Performance at past and present. Also, it helps managements in planning, controlling and decisions- making processes, and its data sources are the information coming from the transactions processing systems (TPS). The concept of executive support systems (ESS) indicates the systems that have been designed to serve the strategic management levels and to help them in making the sensitive decisions in the organization which may need a lot of accuracy, evaluation, and consulting and it has no actions prepared in advance, it also can't be taken by the managers of the transaction or management levels. Data used in those systems are not limited to what is coming from (MIS) and (DSS), but they also depend highly on the data of the external environment that surrounding the organization because any loss in data may occur a significant imbalance which may lead the strategic level managers to lose the ability to take the right decisions which serve the organization in the right way. These systems are working on tracking and screening the data, and to concentrate on the important and sensitive data for the organization in order to reduce managers' time and effort in taking 
the decisions.

\subsection{The Importance of Information Systems}

It is very known to us that the Information Systems are playing a vital role in supporting and succeed the modern organizations activities by providing them with the information required that supports its functions of planning, organizing, controlling, guiding, and taking decisions. Whereas organizations' success depends on its ability to deal with the environmental input like opportunities and threatens. The information that the decision maker is depending on can determine the success of those decisions while dealing with the environmental input, this needs an Information System which includes the quality standards in order to support the managerial activities greatly. Moreover, the Information Systems provide the organization's activities and processes with the information required to achieve their businesses and to document, maintain, and pass it to other activities in the organization that depend on it or integrate with it. Whereas most of the travel and tourism companies activities are depend on information with high quality that require the minimum limit of Information System quality to be able to provide it with this information, so the Information System contributes in consolidate the participation of the Information between the work systems inside and outside the organization. Consequently, it works on the coordination and integration of the work. Therefore, the Information System in those companies is considered the most important thing of the services provided in addition to its competitiveness' level.

The Information System impact is not limited to work systems in organizations, but it impacts the organization as a whole, whereas Information System can impact the competitive edge of the organization through the continuous improvement for production, provide the support required for marketing processes, reduce costs and reduce the management levels in the organizations, and Flexibility of productions. In addition to provide the services by trend forward customers to determine their demands accurately (Martin et al, 2005). It is striking that the impact of Information System is not limited to the organization but it extends to impact the business environment, whereas it affects the products and services shape and nature, also the development Flexibility. Besides it increases the geographical scope of the markets that the organizations are working on, Also to reach new shapes of business, products, and services. The market's circumstances and international competition have increased the importance of Information System in organizations for example: fast-response and improve the products and services, in addition to increase the efficiency and effectiveness of work.

\subsection{Information Systems Quality}

A lot of researchers concern the efficiency of the Information System which concentrates on the functional requirements for Information Systems, for example: the number of tasks that the system can do within specified period. Some people concern the necessity of user's participation in redressing the system's effectiveness process, and the need for measuring the value that the Information System can add to the organization and how it can contribute in achieve the effectiveness for the whole institution. (Delone and Mclean, 2008) reached to the Information System effectiveness form that consists of three dimensions: Information Quality, System Quality, and Services Quality and each one of them should be measured separately 
because it has huge impact on using and user's satisfaction. Thus, this study is trying to learn about the Information Systems Quality level as a part of Information Systems effectiveness components.

Information System Quality can be described as the system's features itself which are system flexibility, system integration, and response time. In addition to user's expectation realization, trust on system, usability, easy to learn, and the benefits achieved from the system. Moreover, some people concentrated on the System Quality as the quality of the treatment process itself which includes the data components, and measure how much the system is sound from the technical side, and how much problems there are according to user's interface coherence, usability, and documentation quality.

Others classified the Information System into two parts: 1. System's features from the perspective of the designer and it is named (System Flexibility) which reflects the fact the system has been designed with useful features without the unnecessary features, and the software amendments can be done easily by the designer. 2. System's features from the perspective of the user and it is named (professional system dimensions) which include the notice that the system is user-friendly, well-documented, it has rapid transformation time advantage, and it uses the new technology to make the system easier. (Gorla, et al 2010).

The Information System features would be the reliability on system, usability (easy- learning, able to be controlled, clarity, able to be understood, and flexibility), speed, adequacy, modernity, information accuracy, work execution, and productivity (Sabherwal et al, 2004). According to Delone form that it is modernized in (Bach, Christian, 2011) study, this study will adopt the Information System Quality dimensions as the following:

1) Adaptability: the ability of the system to adapt according to users' circumstances and demands, and it indicates the system's ability to amend its components, functions, activities, and its integration with the other systems in a way that response to the internal and external work environment circumstances, and what it makes it able to response to the insider and outsider users' demands.

2) Availability: the ability of Information Systems' preparations and facilities to maintain in a status that allows it to achieve its function in the right way under certain circumstances and with the assumption that all the resources are available. This ability can allow the Information System to provide information for users, also information accessibility and retrieving, in addition to obtain the informational support through achieving the user's demands constantly.

3) Reliability: it represents the system's success in achieving goals accurately and successfully in a way that it may be depends on within specific period of time. This tool is considered very important to the Information System Quality dimensions; it aims to find the failure causes in delivering the information and recognize the reason behind it i.e. increase the resistance ability to prevent any fault or failure while delivering the information to users.

4) Response Time: the ability of the system to response to the user's demand on time, and it 
represents the high quality features of the Information System components (software, tools, networks, internet, procedures, and individuals) which may enable it to provide the users with information in the appropriate time, place, and shape. Also it provides support and solutions to the users' problems which they are fit their needs and expectations and can achieve the benefit wanted from the system. Moreover, it represents the system ability in responding to user's needs on time and under any circumstances for example; time of request or the amount of information. This depends on system components features like; processing speed, storage capacity, internet capacity, and system ability to response to big number of users simultaneously.

5) Usability: it indicated how the Information System is easy, practical, and appropriate to use. It also includes the easiness when dealing with the user's interface and with the system's components. Moreover, learning about how to deal with it, or remain remembers how to deal with it, and how much the error is repeated by the user when using the system more than one time and therefore the user's satisfaction on the Information System.

\subsection{The Strategic Flexibility Concept and Importance}

The Strategic Flexibility is the ability of the organization's flexibility to change, whereas it can be able to amend its market share and to adapt rapidly with market's trends, in addition to working on the dynamic amendment through focusing on its strategies (Hayes \& Pisano, 1994). Also, some researchers consider it as the organizations ability to develop new products and enter new markets and industries, not in the traditional concept of Flexibility that focusing on the organization's ability to amend its products amounts according to changeable market requirements (Bhandari, 2004). So the Strategic Flexibility might be the organization ability to determine the changes of the external environment, and response rapidly for it.

The organizations realized the importance of the Strategic Flexibility as a result of its necessity to achieve new competitive advantage besides many reasons (Yonggui \& Hing-Po, 2004):

1) The Strategic Flexibility is considered a condition to increase organizations' ability to face the fast and vital environmental changes that happen in the market in efficiency way. Also, to enable it to manage its activities under these circumstances and that it is necessary to use it in managing the continuous changing status in the high-technical product's market under uncertainty.

2) Enhance the organizations' abilities to response to customers' need and desires that is changing continuously, and to reveal any preferences for customers beside its emphasis for the organization's marketing abilities through the interaction with its customers.

3) Its contribution to increase the organizations' ability to display their products in several markets, and increase its ability to create a real value of customers. In addition to making the organization fast in responding to any change in changeable customers' demands, and it is important to grow up and maintain the business organizations and create opportunities for the organization to improve the life of the society sections. Among 
growth options there are three main alternatives: geographical regions, products/ service, and expand the added value.

The researchers emphasized the role of the Strategic Flexibility in enabling the business organizations to compete in the current circumstances. It enables the organization to change its strategies when their customers transfer from its products to another competitive organization' products that may be attracted them. In addition to that, it helps the organization to create and distribute the real value of the customers and correlate the organization's Performance as a result of the it's ability to compete and increase its effectiveness of communication, planes, and strategies that arriving it to adopt the product offered and mixed- market forms.

\subsection{Strategic Flexibility Dimensions}

The strategic flexibility is consisting of many components that involve development of strategies that it is appropriate to its environment reality in terms of adaptability, succession, ability to be amended and corrected, hedging, revitalization, agility, withstanding shocks, and flexible back off.(De Toni \& Tonchia, 2005).

Five competitive dimensions have been determined in respect with the Strategic Flexibility which they are: Speed; the ability to response rapidly to customers and market demands and entering new techniques and ideas in product; Consistency "the ability to produce a certain product that fulfill the expectations of customers successfully; Acuity "the ability to predict and response to the customers' new desires and needs; Agility " the ability of instant adaptation to several different work environments; Innovativeness" the ability to create new ideas for collect the existing elements in reason to establish new valuable sources, whereas the Varity gives the organization the ability to initiation within a large scale in facing the environmental pressures for example: the variation associated with the organization ability to response to market's different needs through developing a wide lines of production. Whereas Speed is indicating the organization capability and viability in confront the changing needs of environment with high speed which means the shortest possible time to do specific act. Thus, the speed is associated with repeating the re-designing rapidly for production systems in response to the new products requirements. (De Toni \& Tonchia, 2005).

Some studies determined three dimensions for Strategic Flexibility which is the flexibility in providing the product, flexibility in technology, and flexibility in dealing with other organizations. Although the speed and Varity of competition is demonstrating two different dimensions, but on the other hand they are exchanging the impact between them, it is supposed to the organization management to consider the interference's nature between these two dimensions in order to adapt a certain level of Strategic Flexibility that provide the organization the best possible strategic performance. (Bhandari, et. al, 2004).

This study was improved on determining the dimensions of productivity and market's Strategic Flexibility (Abbott \& Banerj 2003, Lamalfa, 2007). The Market Flexibility indicates the organization ability to re-measure its market's efforts in the short run, in reason to response to the surrounding environmental changes. It can be measured through the market 
share and the speed response to customers' demands, in addition to involve into new markets and determine the appropriate market. However, production flexibility indicates the organization ability to manufacture its products to its main markets around the world in short time and competitive costs. It could be measured by the amendment of the existing products, in addition to manufacture new products, amend the productive capacity, control the storage, and the technological development of the production processes. The capability flexibility has been measured based on (Yu, 2012; Li et. al, 2011) which indicates the organization ability to take full advantage of new and most efficient resources that fulfill its customers' needs. Delone and others 2008 have conducted a study titled "Measuring Information Systems Success: Models, Dimensions, Measures, and Interrelationships”.

The study aimed to extract and test the measurement of information systems success elements, it manifested that since Delone and Mclean have develop their form in measure the success of information system, system quality, information quality, services quality, and user's satisfaction. Ninety studies have been examined and its results have been abstracted, a sum of 15 links between these dimensions in respect about the information system success. It has been applied to measure the information system success through the relation test between Delone form success elements on the individual level and organization's context. moreover, Balaban, 2009 has conducted a study titled "Methodological Approaches To Evaluation Of Information System Functionality Performances And Importance Of Successfulness Factors Analysis", the study aimed to manifest the reasons behind the appearance of concerning the evaluation of functional performance of information systems which stems from the importance of information technology in the success organization processes, also by striving forward to evaluate the resources on the organization. The study showed the elements of the evaluation of functional performance for the Information System in respect of inputs, processes, and the system itself, in addition to the importance of the information system elements success from the perception of users, professionals, and administrations.

As (Yuan, et.al, 2010) conducted a study named "Can Strategic Flexibility Help Firms Profit from Product Innovation? "Which aimed to focus on the moderate impact of the Strategic Flexibility (the Flexibility of recourses and coordination) on the relationship between the innovation of the product and the companies' performance in China? The survey population consisted of 850 Chinese institutions which distributed on 8 Chinese cities: (Shandong; Guangdong; Shanghai; Liaoning; Sichuan; Shaanxi; Shanxi; Henna). However, the survey sample was of 607 Chinese institutions that responded to the questionnaire that has been prepared by the researchers. The descriptive analytical approach has been used and that's by developing the questionnaire depending on a group of writers and researchers in the field of questioned study variables. And to achieve that, researchers resorted to use the medians, standard deviations, regression analyses, and trajectory analysis.

The study has reached to many results, the most important was that the moderate impact of the recourses flexibility in the relation between the product innovation and the companies' performance in China was negative impact. (Kakale, et.al, 2010) study titled "Achieving Sustained Innovation Performance Through Strategic Flexibility Of New Product Development" aimed to outline the Strategic Flexibility role in the relation between the 
innovation performance and developing the new product in a sample of companies .The survey population included a group of companies which were 200 companies in many countries which are: Australia, Belgian, Denmark, Netherlands, Finland, Spain, Norway, and Turkey.

The study sample contained from the managers of these companies which remaining 200 managers. The descriptive analytical approach has been used and that's by developing the questionnaire in the field subject study's variables. And to achieve that, the researchers resorted to use the medians, standard deviations, regression analyses, and trajectory analysis. The study has reached many results; the most important was that the Strategic Flexibility plays a minimum role in enhancing the relation between the innovations and developing the new product in the questioned companies. (Yu, 2012) study titled: "Strategic Flexibility, Entrepreneurial Orientation And Firm Performance: Evidence From Small And Medium Sized Business (SMB) In China" that aimed to test the impact of the leading orientation on the performance of the small and medium- sized companies in china, in addition to manifest the impact of the leading orientation on the performance of the small and medium- sized companies in china with the existing of the Strategic Flexibility and the competition sensitivity. The survey population included (500) companies work in technology industry in the east of china, in 3 cities are: (shanghai, Jiangsu, and Zhejiang) .However, the study sample contained these titles: executive manager, chairman, and manager general), a response of (195) countries has been obtained, and after examining the responses, three of them was excluded, to let the total of the sample (192) companies. The researcher used surveyexploratory approach and that's by depending on a questionnaire that some of its questions have been developed by the researcher and others depended on previous studies of the same subject. To achieve that, they used the statistical methods; the most important of them are the discriminate analysis, regression analysis, and trajectory analysis. The study found many results, the most important was the Strategic Flexibility and competitive sensitivity are playing a role in the leading orientation impact on the performance of medium and small-sizes companies in China.

While (Pedarpur, et al, 2013) study was titled:" management information system and their functions, structure, and importance for the managers when they are going to make a decision. This study aimed to evaluate the Management Information Systems components and manifest the importance of its role in making decisions. The research adapted the analytical approach to achieve the study goals. The main concepts of the Management Information Systems and the accurate data features. The most important result of study is that the result from the Management Information Systems is the main element in decision- making process. Beside it supports the organization abilities and increases its opportunities to obtain the competitive advantage.

\subsection{Testing Hypotheses, Discussing Findings, and Recommendations}

Answering the study questions:

The First Question: what are the perceptions of the people -in -question about the Information Systems Quality and its dimensions (Adaptability, Availability, Reliability, Response Time, 


\section{MInstitute ${ }^{\text {Mink }}$}

International Journal of Human Resource Studies

ISSN 2162-3058

2017, Vol. 7, No. 3

and Usability) the travel and tourism companies working in the Jordanian capital Amman?

Through the statistical analysis it can be shown that the general moderate of Information Systems Quality dimensions in the Jordanian travel and tourism companies working in the Jordanian capital Amman has reached (3.55) with high degree. This is clear indicator to the information system success in performing its function perfectly in these companies' activities. And by the analysis of the Information Systems Quality dimensions, it became clear that the dimension (Availability) has ranked as number one with a median of (3.77) and standard deviation of (0.90), it is followed by the dimension (Adaptability) with a median of (3.63) and standard deviation of (0.88), whereas the dimension (Response Time) took the third place with a median of (3.62) and standard deviation of (0.87). Moreover, in the fourth place came the (Reliability) dimension in moderate and a median of (3.49) and standard deviation of (0.86). And in the last place was the (Usability) dimension with a median of (3.46) and standard deviation of (0.83).

The Second Question: what is the level of the Strategic flexibility the travel and tourism companies working in the Jordanian capital Amman according to the perceptions of the people in question?

The statistical analysis results came to clarify that the overall median for the Strategic Flexibility in the Jordanian travel and tourism companies working in the Jordanian capital Amman has reached (3.45). This means that the perceptions of study's sample individuals about the level of the Strategic Flexibility dimensions availability were at moderate level, this is clear indicator to the maturity of these companies, especially since the religious tourism is taking a considerable place in the offices of these agencies. And by the analysis of the Strategic Flexibility dimensions, it became clear that the dimension (Product Flexibility) has ranked as number one with a median of (3.49) and standard deviation of (0.95), it is followed by the dimension (Market Flexibility) with a median of (3.46) and standard deviation of (0.87), whereas the dimension (Capabilities Flexibility) took the last place with a median of (3.47) and standard deviation of (0.96).

\subsection{Hypotheses Test}

First Main Hypothesis: H01 There is no statistical significance impact at the significance level $(\alpha \leq 0.05)$ for the Information Systems Quality and its dimensions: (Adaptability, Availability, Reliability, Response Time, and Usability) from the perceptions of the people in question on the Strategic Flexibility in tourism and travel companies working in Jordan capital Amman. To test this hypothesis, Multiple-Regression Analysis Test has been used as it shows in table no.2: 


\section{Macrothink}

International Journal of Human Resource Studies

ISSN 2162-3058

2017, Vol. 7, No. 3

Table 2. The results of Multiple-Regression Analysis to test the impact of Information Systems Quality dimensions on the Strategic Flexibility in tourism and travel companies working in Jordan capital Amman.

\begin{tabular}{|l|l|l|l|l|l|}
\hline $\begin{array}{l}\text { Independent } \\
\text { Dimension }\end{array}$ & B & $\begin{array}{l}\text { Standard } \\
\text { Error }\end{array}$ & Beta & $\begin{array}{l}\text { Observed (T) } \\
\text { Value }\end{array}$ & $\begin{array}{l}\text { Significance Level } \\
\text { of }(\mathrm{T})\end{array}$ \\
\hline $\begin{array}{l}\text { Regression } \\
\text { Constant }\end{array}$ & 0.3998 & 0.099 & & 2.8 & 0.006 \\
\hline Adaptability & 0.0519 & 0.095 & 0.071 & 0.70 & 0.498 \\
\hline Availability & 0.2645 & 0.075 & 0.363 & 2.8 & 0.008 \\
\hline Reliability & -0.0339 & 0.075 & -0.052 & -0.45 & 0.622 \\
\hline Response Time & 0.3165 & 0.085 & 0.247 & 3.9 & 0.006 \\
\hline Usability & 0.3934 & 0.086 & 0.456 & 3.1 & 0.001 \\
\hline
\end{tabular}

As can be seen from table no. (2) and from the values of (T) test, that the sub- dimensions (Availability, Response Time, and Usability) have their impact on the Strategic Flexibility in tourism and travel companies working in Jordan capital Amman by the significant of the coefficient (Beta) for these variables, and by the significant of the high values of observed (T) regarding its tabular value at the significance level $(\alpha \leq 0.05)$. The observed (T) value of these sub-dimensions reached $(2.8,3.9,3.1)$ respectively, which are significant values at the significance level $(\alpha \leq 0.05)$. For what has mentioned, it requires the following: to reject the null hypothesis which stated that there is no statistical significance impact at the significance level $(\alpha \leq 0.05)$ for the Information Systems Quality and its dimensions: (Adaptability, Availability, Reliability, Response Time and Usability) on the Strategic Flexibility, whereas it was found that there is impact for the three dimensions (Availability, Response Time, and Usability). However, the reason behind that there is no impact for the dimensions (Adaptability and Reliability) is the work pressure on these companies especially that the religious tourism is year-rounded.

The Stepwise Multiple Regression Analysis has been done to determine the importance of each independent variable individually in contributing in the mathematical form which represents the impact of Information Systems Quality on the Strategic Flexibility in tourism and travel companies working in Jordan capital Amman. As shown in the table no. (3).

Table 3. Stepwise Multiple Regression Analysis results to predict the Strategic Flexibility through the Information Systems Quality dimensions as Independent Variables.

\begin{tabular}{|l|l|l|l|l|}
\hline $\begin{array}{l}\text { The order of the Independent } \\
\text { Variables Access in the } \\
\text { Prediction Equation }\end{array}$ & $\begin{array}{l}\mathrm{R}^{2} \text { value } \\
\text { Determination } \\
\text { coefficient }\end{array}$ & $\mathrm{B}$ & $\begin{array}{l}\text { Observed(T) } \\
\text { value }\end{array}$ & $\begin{array}{l}\text { Significance } \\
\text { Level of (T) }\end{array}$ \\
\hline Constant & & 0.398 & 4.156 & 0.009 \\
\hline Usability & 0.66 & 0.456 & 4.342 & 0.005 \\
\hline Availability and Usability & 0.71 & 0.357 & 4.023 & 0.002 \\
\hline $\begin{array}{l}\text { Availability, Response Time, } \\
\text { and Usability }\end{array}$ & 0.80 & 0.456 & 4.229 & 0.004 \\
\hline
\end{tabular}


It can be shown from table no. 3, which manifests the order of Independent Variables access in the Regression equation, that the dimension (Usability) was in the first rank, whereas it explained $(66.1 \%)$ of the total variation in the Strategic Flexibility in tourism and travel companies working in Jordan capital Amman. The second rank was the (Availability) dimension; both of the dimensions: Usability with Availability explained (71\%) of the total variation in the Strategic Flexibility in tourism and travel companies working in Jordan capital Amman, the dimension(Availability) alone explained approximately (7.9\%). Finally, the (Response Time) dimension which explained beside the previous mentioned dimensions accounted for $(80 \%)$ of the total variation in the Strategic Flexibility in tourism and travel companies working in Jordan capital Amman. The following Sub-hypotheses are stemmed from this hypothesis:

First sub-hypothesis: H01-1 There is no statistical significance impact at the significance level $(\alpha \leq 0.05)$ for the Information Systems Quality and its dimensions: ( Adaptability, Availability, Reliability, Response Time and Usability) in Market Flexibility dimension as one of the Strategic Flexibility dimensions in tourism and travel companies working in Jordan capital Amman. The Stepwise Multiple Regression Analysis has been used to test this hypothesis and the results are showed in table no.4.

Table no. (4): the results of the Stepwise Regression Analysis to test the impact of the Information System Quality dimensions on the dimension (Market Flexibility) in the travel and tourism companies working in the Jordanian capital Amman.

\begin{tabular}{|l|l|l|l|l|l|l|}
\hline $\begin{array}{l}\text { Independent } \\
\text { variable }\end{array}$ & $\mathrm{R}^{2}$ value & $\mathrm{B}$ & $\begin{array}{l}\text { Standard } \\
\text { error } \\
\text { Determination } \\
\text { coefficient }\end{array}$ & Beta & $\begin{array}{l}\text { Observed T } \\
\text { value }\end{array}$ & Significance \\
\hline $\begin{array}{l}\text { Regression } \\
\text { constant }\end{array}$ & 0.869 & 0.056 & 0.065 & & 0.359 & 0.004 \\
\hline Adaptability & & 0.258 & 0.087 & 0.178 & 3.533 & 0.019 \\
\hline Availability & & 0.045 & 0.078 & 0.038 & 0.675 & 0.08 \\
\hline Reliability & & 0.325 & 0.088 & 0.207 & 3.756 & 0.009 \\
\hline Response time & & 0.620 & 0.075 & 0.205 & 4.651 & 0.004 \\
\hline Usability & & 0.56 & 0.095 & 0.386 & 6.845 & 0.499 \\
\hline
\end{tabular}

It can be shown from table no. 4 and from the following up for the test of (T) that the sub dimensions (Adaptability, Reliability, Response Time, and Usability) has impact on the Market Flexibility in the travel and tourism companies working in the Jordanian capital Amman by the significance of (Beta) coefficients for these variables as it appears in the table, also with the significance of the high values of the observed (T) related to its tabular value at the significant level ( $\alpha \leq 0.05$ ) whereas the observed $(\mathrm{T})$ values reached $(4.651,3.756,3.353)$ respectively. They are significant values at the significance level $(\alpha \leq 0.05)$. Based on what mentioned, the following is required: to reject the null hypothesis which stated that there is no statistical significant impact at the significance level for the Information Systems Quality dimensions (Adaptability, Availability, Reliability, Response Time and Usability) on the 


\section{Mll Macrothink}

International Journal of Human Resource Studies

ISSN 2162-3058

2017, Vol. 7, No. 3

Market Flexibility in the travel and tourism companies working in the Jordanian capital Amman. The reason behind there is no impact for the dimension (Adaptability) on the Market Flexibility can refer to the users of the system which most of them are tourists from the outside of the country, besides they have multi cultures that make it hard for the system to adapt with their demands variety.

The Stepwise Regression Analysis has been done to determine the importance of each independent variable in contributing with the mathematical form which represents the impact of the information system quality dimensions (Adaptability, Availability, Reliability, Response Time and Usability) on the Market Flexibility in the travel and tourism companies working in the Jordanian capital Amman. See table no. (5):

Table 5. The results of the Stepwise Multiple Regression Analysis to predict the Market Flexibility dimension through the information system quality dimensions as Independent Variables:

\begin{tabular}{|l|l|l|l|l|}
\hline $\begin{array}{l}\text { The order of the Independent } \\
\text { Variables Access in the } \\
\text { Prediction Equation }\end{array}$ & $\begin{array}{l}\mathrm{R}^{2} \text { value } \\
\text { Determination } \\
\text { coefficient }\end{array}$ & $\mathrm{B}$ & $\begin{array}{l}\text { Observed(T) } \\
\text { value }\end{array}$ & $\begin{array}{l}\text { Significance } \\
\text { Level of (T) }\end{array}$ \\
\hline Constant & 0.785 & 0.039 & 0.365 & 0.841 \\
\hline Usability & 0.305 & 6.834 & 0.001 \\
\hline Reliability and usability asability and & 0.878 & 0.282 & 3.551 & 0.007 \\
\hline $\begin{array}{l}\text { Reliability , usability , } \\
\text { Response Time }\end{array}$ & 0.844 & 4.372 & 0.001 \\
\hline $\begin{array}{l}\text { Reliability } \\
\text { Response Time, and } \\
\text { Adaptability }\end{array}$ & 0.198 & 3.357 & 0.019 \\
\hline
\end{tabular}

It can be shown from table no. (5), which manifests the order of Independent Variables access in the Regression equation, that the dimension (Usability) was in the first rank, whereas it explained $(7.85 \%)$ of the total variation in the Market Flexibility dimension in tourism and travel companies working in Jordan capital Amman. The second rank was the (Reliability) dimension; both of the dimensions: Usability with Reliability explained (72.7\%) of the total variation in the Market Flexibility dimension in tourism and travel companies working in Jordan capital Amman, the dimension (Response Time) beside the two previous dimensions has explained approximately $(0.878 \%)$ of the total variation in the Market Flexibility dimension in tourism and travel companies working in Jordan capital Amman. Finally, the (adaptability) dimension accessed with all mentioned dimensions and explained an accounted for $(0.844 \%)$ of the total variation in the Market Flexibility dimension in tourism and travel companies working in Jordan capital Amman.

Second Sub-Hypothesis: H01-2 There is no statistical significance impact at the significance level $(\alpha \leq 0.05)$ for the Information Systems Quality and its dimensions: (Adaptability, Availability, Reliability, Response Time and Usability) in Product Flexibility dimension as one of the Strategic Flexibility dimensions in tourism and travel companies working in 
Jordan capital Amman. Multiple-Regression Analysis Test has been used as it shows in table no. (6):

Table 6. the results of the Stepwise Multiple Regression Analysis to test the impact of the Information System on the Product Flexibility dimension in the management of the travel and tourism companies working in Jordanian capital Amman.

\begin{tabular}{|l|l|l|l|l|l|l|}
\hline $\begin{array}{l}\text { Independent } \\
\text { Dimension }\end{array}$ & $\begin{array}{l}\mathrm{R}^{2} \text { value } \\
\text { Determination } \\
\text { coefficient }\end{array}$ & $\mathrm{B}$ & $\begin{array}{l}\text { Standard } \\
\text { Error }\end{array}$ & Beta & $\begin{array}{l}\text { Observed } \\
(\mathrm{T}) \text { Value }\end{array}$ & $\begin{array}{l}\text { Significance } \\
\text { Level of }(\mathrm{T})\end{array}$ \\
\hline $\begin{array}{l}\text { Regression } \\
\text { Constant }\end{array}$ & 0.871 & 0.427 & 0.275 & & 1.438 & 0.008 \\
\hline Adaptability & & 0.089 & 0.121 & 0.075 & 0.914 & 0.315 \\
\hline Availability & & 0.453 & 0.025 & 0.407 & 5.571 & 0.001 \\
\hline Reliability & & 0.296 & 0.115 & 0.156 & 1.808 & 0.088 \\
\hline Response Time & & 0.258 & 0.107 & 0.128 & 1.249 & 0.314 \\
\hline Usability & & 0.269 & 0.121 & 0.241 & 5.587 & 0.002 \\
\hline
\end{tabular}

As can be seen from table no. (6) and from the following up of (T) values, that the sub-dimensions (Availability and Usability) have their impact on the Product Flexibility in tourism and travel companies working in Jordan capital Amman by the significant of the coefficient (Beta) for these variables, and by the significant of the high values of observed (T) regarding its tabular value at the significance level $(\alpha \leq 0.05)$. The observed $(\mathrm{T})$ values of these sub-dimensions reached $(5.571,5.587)$ respectively, which are significant values at the significance level $(\alpha \leq 0.05)$. For what has mentioned, it requires the following: to reject the null hypothesis which stated that there is no statistical significance impact at the significance level $(\alpha \leq 0.05)$ for the Information Systems Quality and its dimensions: (Adaptability, Availability, Reliability, Response Time and Usability) on the Product Flexibility, whereas it was found that there is impact for the two dimensions (Availability and Usability). The Stepwise Multiple Regression Analysis has been done to determine the importance of each independent variable individually in contributing in the mathematical form which represents the impact of Information Systems Quality dimensions (Adaptability, Availability, Reliability, Response Time and Usability) on the Product Flexibility in tourism and travel companies working in Jordan capital Amman.

Table 7. Stepwise Multiple Regression Analysis results to predict the Product Flexibility through the Information Systems Quality dimensions as Independent Variables.

\begin{tabular}{|l|l|l|l|l|}
\hline $\begin{array}{l}\text { The Order of the Independent } \\
\text { Variables Access in the } \\
\text { Prediction Equation }\end{array}$ & $\begin{array}{l}\mathrm{R}^{2} \text { value } \\
\text { Determination } \\
\text { coefficient }\end{array}$ & $\mathrm{B}$ & $\begin{array}{l}\text { Observed(T) } \\
\text { value }\end{array}$ & $\begin{array}{l}\text { Significance } \\
\text { Level of (T) }\end{array}$ \\
\hline Constant & & 0.502 & 1.791 & 0.003 \\
\hline Availability & 0.772 & 0.366 & 4.316 & 0.000 \\
\hline Availability and Usability & 0.815 & 0.484 & 5.852 & 0.000 \\
\hline
\end{tabular}




\section{Mll Macrothink}

International Journal of Human Resource Studies

ISSN 2162-3058

2017, Vol. 7, No. 3

It can be shown from table no. (7), which manifests the order of Independent Variables access in the Regression equation, that the dimension (Availability) was in the first rank, whereas it explained $(0.772 \%)$ of the total variation in the Product Flexibility in tourism and travel companies working in Jordan capital Amman. At the second rank were the (Availability and Usability) dimensions; both of the dimensions: Usability with Availability explained (0.815\%) of the total variation in the dimension (Product Flexibility) in tourism and travel companies working in Jordan capital Amman.

Third Sub-Hypothesis: H01-3 There is no statistical significance impact at the significance level $(\alpha \leq 0.05)$ for the Information Systems Quality and its dimensions: (Adaptability, Availability, Reliability, Response Time and Usability) in Capabilities Flexibility dimension as one of the Strategic Flexibility dimensions in tourism and travel companies working in Jordan capital Amman. To test this hypothesis, Multiple-Regression Analysis Test has been used as it shows in table no. (8):

Table 8. The results of the Stepwise Multiple Regression Analysis to test the impact of the Information System on the Capabilities Flexibility dimension in the travel and tourism companies working in Jordanian capital Amman.

\begin{tabular}{|l|l|l|l|l|l|l|}
\hline $\begin{array}{l}\text { Independent } \\
\text { Dimension }\end{array}$ & $\mathrm{R}^{2}$ value & $\mathrm{B}$ & $\begin{array}{l}\text { Standard } \\
\text { Error } \\
\text { Determination } \\
\text { coefficient }\end{array}$ & Beta & $\begin{array}{l}\text { Observed } \\
(\mathrm{T}) \text { Value }\end{array}$ & $\begin{array}{l}\text { Significance } \\
\text { Level of (T) }\end{array}$ \\
\hline $\begin{array}{l}\text { Regression } \\
\text { Constant }\end{array}$ & 0.591 & 1.134 & 0.223 & & 4.301 & 0.003 \\
\hline Adaptability & & -0.195 & 0.153 & -0.094 & -0.646 & 0.611 \\
\hline Availability & & 0.339 & 0.194 & 0.198 & 1.821 & 0.096 \\
\hline Reliability & & -0.215 & 0.180 & -0.086 & -0.813 & 0.372 \\
\hline Response Time & & 0.211 & 0.142 & 0.351 & 3.188 & 0.032 \\
\hline Usability & & 0.198 & 0.148 & 0.241 & 1.204 & 0.130 \\
\hline
\end{tabular}

As can be seen from table no. (8), and from the following up of (T) values, that the sub-dimensions (Response Time) have its impact on the Capabilities Flexibility in tourism and travel companies working in Jordan capital Amman by the significant of the coefficient (Beta) for these variables, and by the significant of the high values of observed $(\mathrm{T})$ regarding its tabular value at the significance level $(\alpha \leq 0.05)$. The observed (T) values of this sub-dimension reached (3.188), which is significant value at the significance level $(\alpha \leq 0.05)$. For what has mentioned, it requires the following: to reject the null hypothesis which stated that there is no statistical significance impact at the significance level $(\alpha \leq 0.05)$ for the Information Systems Quality and its dimensions: (Adaptability, Availability, Reliability, Response Time and Usability) on the Capabilities Flexibility, whereas it was found that there is impact for the dimension (Response Time).

The Stepwise Multiple Regression Analysis has been done to determine the importance of each Independent Variable individually in contributing to the mathematical form which 
represents the impact of Information Systems Quality dimensions (Adaptability, Availability, Reliability, Response Time and Usability) on the Capabilities Flexibility in tourism and travel companies working in Jordan capital Amman.

Table 9. The Stepwise Multiple Regression Analysis results to predict the Capabilities Flexibility through the Information Systems Quality dimensions as Independent Variables.

\begin{tabular}{|l|l|l|l|l|}
\hline $\begin{array}{l}\text { The Order of the Independent } \\
\text { Variables Access in the } \\
\text { Prediction Equation }\end{array}$ & $\begin{array}{l}\mathrm{R}^{2} \text { value } \\
\text { Determination } \\
\text { coefficient }\end{array}$ & $\mathrm{B}$ & $\begin{array}{l}\text { Observed(T) } \\
\text { value }\end{array}$ & $\begin{array}{l}\text { Significance } \\
\text { Level of (T) }\end{array}$ \\
\hline Constant & 0.561 & 1.113 & 3.666 & 0.000 \\
\hline Response Time & 0.389 & 0.347 & 3.027 & 0.003 \\
\hline $\begin{array}{l}\text { Availability and Response } \\
\text { Time }\end{array}$ & 0.275 & 2.441 & 0.016 \\
\hline
\end{tabular}

It can be shown from table no. (9), which manifests the order of Independent Variables access in the Regression equation, that the dimension (Response Time ) was at the first rank, whereas it explained $(0.561 \%)$ of the total variation in the Capabilities Flexibility in tourism and travel companies working in Jordan capital Amman. At the second rank were the (Availability and Response Time) dimensions; both of the dimensions: Response Time with Availability explained $(0.389 \%)$ of the total variation in the dimension (Capabilities Flexibility) in tourism and travel companies working in Jordan capital Amman.

\section{Findings}

The study reached to the following results:

1) The perceptions of the people in question were at high degree toward the level of Information Systems Quality, whereas the perceptions of the people in question toward the Strategic Flexibility were moderate.

2) There is statistical significance for the Information Systems Quality dimensions: (Adaptability, Availability, Reliability, Response Time and Usability) on the Strategic Flexibility for tourism and travel companies working in Jordan capital Amman.

3) There is statistical significance for the Information Systems Quality dimensions: (Adaptability, Availability, Reliability, Response Time and Usability) on the dimension (Market Flexibility) for tourism and travel companies working in Jordan capital Amman.

4) There is statistical significance for the Information Systems Quality dimensions: (Adaptability, Availability, Reliability, Response Time and Usability) on the dimension (Product Flexibility) for tourism and travel companies working in Jordan capital Amman.

5) There is statistical significance for the Information Systems Quality dimension: (Response Time) on the dimension (Capabilities Flexibility) for tourism and travel companies working in Jordan capital Amman. 


\section{Macrothink}

International Journal of Human Resource Studies

ISSN 2162-3058

2017, Vol. 7, No. 3

\section{Recommendations}

Based on the study results, the researcher recommends the following:

1) The need to dedicate attention to provide an official and non-official electronic communication network that facilitate achieving works, beside contribute to facilitate the exchanging of information and idea between all employees in the business sections of the companies in question.

2) Draw the attention of the administrations of the tourism and travel companies working in Jordan capital Amman toward the following:

3) Enhancing the Information Systems Quality level that the study found its importance through the continuous updating for the systems' efficiency, in addition to adapt the latest developments in information systems.

4) Taking into consideration the perspectives of the Information Systems' users when updating the systems design in order to improve the dimensions of systems adaptability.

5) Pay attention to provide the employees training in the systems quality dimensions and taking them around the company's different departments to experience different aspects of systems quality.

6) Drawing the attention of the researchers to conduct more studies concerning the Information System Services Quality, Information Quality, and the Strategic Flexibility in order to be able to complete the elements of Information Systems effectiveness.

\section{Acknowledgement}

The research is sub Thanks for Prof.Aktham AL Sarayreh

\section{References}

Abbott, A., \& Banerji, K. (2003). Strategic Flexibility and Firm Performance: The Case of US Based Transnational Corporations. Global Journal of Flexible Systems Management, 9, 42-66.

Al-Hudhaif, S. A. (2010). Measuring Quality of Information System Services in Manufacturing Organizations in Riyadh. JKAU: Econ. \& Adm., 24(1), 151-171.

Bach, C., Salvatore, B., \& others. (2011). Factor Analysis in Measuring Information Systems Effectiveness. Proceedings of the 2011 ASEE Northeast Section Annual Conference.

Balaban. Gordan. P. (2009). Methodological Approaches to Evaluation of Information System Functionality Performances and Importance of Successfulness Factors Analysis. Journal of Management Information Systems, 4(2), 011-017.

Baribeau, P. (2012). 3 Easy ways to Promote Organizational Loyalty, www. tribehr.com/blog, 15Jul,2013

Baribeau, P. (2013). 3 Easy ways to Promote Organizational Loyalty, www.tribehr.com, 


\section{Macrothink}

10Jan, 2014.

Bhandari, G. Bliemel, M. Harold, A., \& Hassanein, Kh. (2004). Flexibility in e-Business Strategy: A Requirement for Success. Global Journal of flexible Systems Management, 5, $11-22$.

Davis, O. (1985). Management information systems: conceptual foundations, structure, and development, McGraw Hill Book Company, New Yourk, USA

De Toni, A. D., \& Tonchia, S. (2005). Definitions and Linkages between Operational and Strategic Flexibilities. Omega, 33(6), 516-525.

DeLone, W. H., McLean, E. R., \& Petter, S. (2008). Measuring information Systems success: models, dimensions, measures, and interrelationships. European Journal of Information Systems, 17, 236-263.

Gorla, N., Somers, T. M., \& Wong, B. (2010). Organizational impact of system quality, information quality, and service quality. Journal of Strategic Information Systems, 19, 207-228.

Gryna, F. M., \& others. (2007). Juran's Quality Planning and Analysis for Enterprise Quality, McGraw-Hill Series in Industrial Engineering and Management, $5^{\text {th }}$ edition.

Gupta, A. (2011). Advantages and disadvantages of DBMS. www.gobookee.org/get_book , 01Feb, 2014.

Hayes, R. H., \& Pisano, G. E. (1994). Beyond World-Class: the New Manufacturing Strategy. Harvard Business Review, 72, 77-86.

Kekale, T., Weerd-Nederhof, Petra De, Visscher, K., \& Bos, G. (2010). Achieving sustained innovation performance through strategic flexibility of new product development. International Journal of Innovation and Learning, 7(4), 377-393.

Lamalfa, K. (2008). The Top 11 Ways to Increase Your Employee Loyalty. www.allegiance.com, 20Jul, 2013.

Laudon, K. C., \& Laudon, J. P. (2007). Management Information Systems: Managing the Digital Firm, 10thed, New Jersey: Prentice-Hall, Person Education, Upper Saddle River.

Li, Y., Su, Z. F., Liu, Y., \& Li, M. F. (2011). Fast adaptation, strategic flexibility and entrepreneurial roles. Chinese Management Studies, 5(3), 256-271.

Martin, N., Gregor, S., \& Hart, D. (2005). The social dimension Of business and IS- IT alignment Case studies of six public- sector Organizations. Australian Accounting Review, 15(3), 28- 38.

O'Brien, James, Marakas. (2011). Management Information Systems, 10E, 2011, The Mc Graw-Hill Companies.

Pedarpur, Zarrodi, Et al. (2013). Management Information system, Functions, Structure and its Importance In Manager's Decision Making. Islamic Azad University, Iran, 
Interdisciplinacy Journal of Contemporary Research In Business, 4(10).

Sabherwal, R., Jeyarajm A., \& Chowa, C. (2004). Information Systems Success: Dimensions and Determinants, University of Missouri.

Yonggui, W., \& Hing-po, Lo, (2004). Customer-Focused Performance and its key Resource-Based Determinations: An Integrated Framework. Customer Relationship, 14, 34 59.

Yu, F. F. (2012). Strategic flexibility, entrepreneurial orientation and firm performance: Evidence from small and medium-sized business (SMB) in China. African Journal of Business Management, 6(4), 1711-1720.

Yuan, L., Su, Z. F., \& Liu, Y. (2010). Can strategic flexibility help firms profit from product innovation? Technovation, 30, 300-309.

\section{Copyright Disclaimer}

Copyright for this article is retained by the author(s), with first publication rights granted to the journal.

This is an open-access article distributed under the terms and conditions of the Creative Commons Attribution license (http://creativecommons.org/licenses/by/4.0/). 